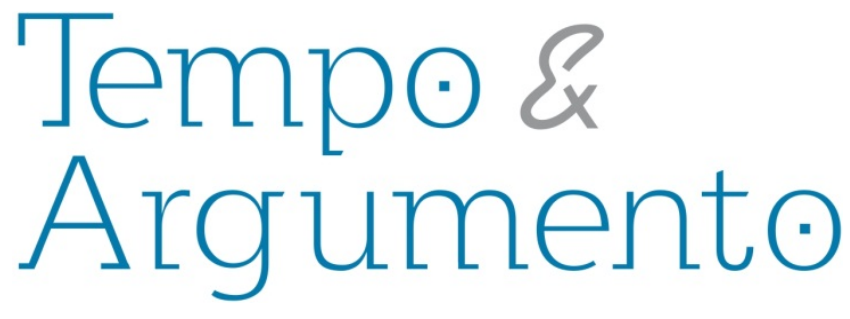

\title{
Teoria da História - a escrita, o lugar do morto e do assombro: diálogos com Michel de Certeau ${ }^{1}$
}

\begin{abstract}
Resumo
Pretende-se problematizar a escrita da História com base em uma parte da teoria do historiador francês Michel de Certeau. Para tanto, abordam-se outros autores, de lugares acadêmicos distintos, por meio dos quais se promovem diálogos epistemológicos com Certeau. A análise teórica que se segue busca dialogar com um conceito de escrita que considera a História como uma "escrita de mortos". Expressões como escrita, narrativa, representação, morte e assombro são consideradas com o fito na "problematização" que se apresenta. De uma parte da obra de Michel de Certeau, almeja-se uma polissemia em contato com diferentes historiadores apresentados no desenvolvimento do texto; fazse alusão a um episódio da peça shakespeariana "Hamlet" e às noções psicanalíticas apresentadas por Michel de Certeau com fulcro em textos de Sigmund Freud e Jacques Lacan.
\end{abstract}

Palavras-chave: Teoria da História. Escrita da História. História.

\section{Leandro Seawright Alonso}

Doutor em História Social pela Universidade de São Paulo (USP). Estágio Pós-Doutoral na Universidade de São Paulo (USP). Professor

Colaborador na Universidade Federal da Grande Dourados (UFGD).

Dourados, Mato Grosso do Sul - BRASIL leandroneho@gmail.com

\section{Para citar este artigo:}

SEAWRIGHT, Leandro A. Teoria da História - a escrita, o lugar do morto e do assombro: diálogos com Michel de Certeau. Revista Tempo e Argumento, Florianópolis, v. 9, n. 21, p. 375 401. maio/ago. 2017.

DOI: $10.5965 / 2175180309212017375$

http://dx.doi.org/10.5965/2175180309212017375

\footnotetext{
${ }^{1}$ Agradeço ao Prof. Dr. José Antonio Vasconcelos (área de Teoria da História na Universidade de São Paulo FFLCH/USP), pela contribuição durante a escrita deste artigo.
} 


\title{
Theory of History - the writing, the place of the dead and the astonishment: dialogues with Michel de Certeau
}

\begin{abstract}
It is intended to discuss the writing of history based on a part of the theory of the French historian Michel de Certeau. Therefore, we approach other authors, from different academic places, through which epistemological dialogues with Certeau are promoted. The theoretical analysis that follows seeks to dialogue with a concept of writing that considers history as a "writing the dead." Words like writing, narrative, representation, death and "amazement" are considered for the purposes of questioning at hand. A part of the work of Michel de Certeau, converses with different historians presented the development of the text; It is made allusion to an episode of the Shakespearean play Hamlet and psychoanalytic notions presented by Certeau based on Sigmund Freud and Jacques Lacan.
\end{abstract}

Keywords: Theory of History. Writing of History. History.

\section{Apresentação}

Sem alimentar reiteradamente o interessante debate teórico acerca das consideradas novas tendências historiográficas entre a história-narrativa e a históriaproblema (VASCONCELOS, 2010), assim como os pressupostos da "virada linguística" (IGGERS, 1997), entre outras possibilidades no campo da reflexão epistêmica, problematiza-se, no artigo que se segue, a escrita da História por meio de três temas basilares - subitens analíticos: A passagem do historiador à escrita; O espectro da morte na escrita da História e; O assombro da História: um jogo da vida e da morte. Tais temas derivam, pois, de partes da obra do historiador francês Michel de Certeau, sobretudo constantes nos seguintes livros: “A Escrita da História”, “A Invenção do Cotidiano: Artes 
de Fazer" e "História e Psicanálise: entre ciência e ficção". A proposta que se segue perscruta exegeticamente a reflexão de Certeau sobre uma parte da "operação historiográfica" revivescida no debate teórico que, entrementes, considera as expressões: narrativa, representação, morte, assombro; mas, neste artigo, procura-se encandecer a terminologia empregada por Certeau não sem problematizá-la em diálogo com historiadores de diferentes escolas teóricas, bem como com autores das diferentes Ciências Humanas e Sociais; não se tem a pretensão, diga-se, de submetê-los a uma pretensa análise completa. Ao contrário, vicejam-se os fragmentos, tais como, entre outros, um episódio da peça shakespeariana Hamlet ${ }^{2}$ com a intenção de aludir ao tema do assombro, posto que, para Certeau, a escrita da História põe em evidência os mortos, as populações de mortos. De que maneira se lhes encarnam as narrativas senão, neste caso, por uma "operação historiográfica”?

Da referida "operação historiográfica" - de onde se parte e se instrui a reflexão Certeau aduz que consiste em

recortar o dado segundo uma lei presente, que se distingue do seu "outro" (passado), distanciando-se com relação a uma situação adquirida e marcando, assim, por um discurso, a mudança efetiva que permitiu esse distanciamento. Assim, a operação histórica tem um efeito duplo. Por um lado, historiciza o atual. Falando mais propriamente, ela presentifica uma situação vivida. Obriga a explicitar a relação da razão reinante com um lugar próprio que, por oposição a um "passado", se torna o presente [...] a imagem do passado mantém o seu valor primeiro de representar aquilo que falta [...] o lugar que ela destina ao passado é igualmente um modo de dar lugar a um futuro. (CERTEAU, 2011, p. 8889)

Para Certeau, ainda, a História como operação pressupõe: “compreendê-la como a relação entre um lugar (um recrutamento, um meio, uma profissão etc.), procedimentos de análise (uma disciplina) e a construção de um texto (uma literatura)"; e, por conseguinte, a "operação histórica se refere à combinação de um lugar social, de práticas

\footnotetext{
${ }^{2}$ A peça de Hamlet, em perspectiva psicanalítica, foi estudada para além da teoria freudiana, por Jones (1970) e Lacan (1986). Freud fez alusão à Hamlet em diferentes textos, e, inclusive, no seguinte clássico: "A interpretação dos sonhos" (1900). Por isso, a menção a um episódio de Hamlet, neste artigo, deve-se à menção de Certeau e à apropriação epistêmica deste historiador enquanto fez cruzamentos teóricos entre a História e a psicanálise.
} 
'científicas' e de uma escrita” (CERTEAU, 2011, p. 46 - 47). Ao contrário de abdicar da discussão do lugar social, das práticas científicas, porém, neste artigo a ênfase teórica se estabelece a partir da concepção de Certeau sobre a escrita no âmbito da nominada “operação historiográfica”.

Ao abordar a Terceira Geração da Escola dos Annales a partir de 1968, Peter Burke, em perspectiva introdutória, suscita a chamada "viragem antropológica" que, segundo disse, "pode ser descrita, com mais exatidão, como uma mudança em direção à antropologia cultural ou simbólica" por parte de diferentes historiadores (BURKE, 1991, p. 66). Se antes a relação entre a História e a Antropologia eram exíguas - não raras vezes tensivas (VASCONCELOS, 2005, p. 127) -, ou apenas como oportunidade de "sobrevoo", conforme definiu Burke, os historiadores da Escola dos Annales, a partir das décadas de 1970 e 1980, entretanto, "demonstraram intenções mais sérias" com a aproximação de ambos os campos de estudos: ponderou-se, então, sobre a "antropologia histórica" ou a “etno-história” (BURKE, 1991, p. 66). Entre outros autores, apareceram frequentemente em notas de rodapé os nomes de Erving Goffman, Victor Turner, Pierre Bourdieu e Michel de Certeau; este último, foi situado por Burke com base nas seguintes considerações laudatórias:

Outra influência ampla é a do falecido Michel de Certeau, um jesuíta especialista na história da religião. Contudo, era impossível atá-lo a uma única disciplina. Foi, entre outras coisas, psicanalista, e sua análise dos casos de possessão diabólica durante o século XVII, original e importante [...] Mais influentes, porém, foram suas contribuições em outros três campos. Juntamente com dois historiadores do grupo dos Annales, escreveu um estudo pioneiro sobre a política da linguagem, analisando pesquisa sobre dialetos locais, realizada durante a Revolução Francesa pelo abade Gregoire, a qual refletia o desejo do regime revolucionário por uniformidade e centralização [...] Organizou também um estudo coletivo sobre a vida cotidiana contemporânea francesa, em que rejeitou o mito do consumidor passivo e enfatizou o que denominou "o consumo como produção"; em outras palavras, a criatividade do povo comum em adaptar os produtos fabricados em série (dos móveis aos dramas televisivos) às suas necessidades pessoais [...] O mais importante de tudo, talvez, sejam seus ensaios sobre a escrita da história, concentrando-se sobre o processo que descreve como a construção do "outro" (os índios do Brasil, por exemplo), frequentemente como o inverso da imagem que o escritor tem de si mesmo. (BURKE, 1991, p. 67) 
Tenciona-se, então, problematizar - sem quaisquer pretensões de esgotamento ou completude - a escrita da História como consequência da experiência do historiador em produzir/estudar os "discursos" ladeados pelas análises procedidas a partir da “operação historiográfica”. Conforme o excerto acima, de Burke, considera-se, para tanto, um lugar de produção inovador e criativo para Certeau, cuja experiência de produção teórica influenciou não somente uma parte da chamada Terceira Geração da Escola dos Annales, mas outros acadêmicos que se inspiraram no movimento historiográfico francês do século XX. Almeja-se mencionar - em polifonia declarada autores de diferentes lugares epistemológicos em diálogo com Certeau, dos mais diversos acadêmicos como o marxista Eric Hobsbawm, aos pertencentes à mesma Escola dos Annales de outras temporalidades, como Marc Bloch, bem como, ainda, aqueles que trataram diretamente da obra de Certeau como Roger Chartier; não obstante, busca-se o cruzamento teórico e interpretativo, sem grandes recorrências, de obras introdutórias como a do historiador Peter Burke às mais intrincadas como - apenas en passant - a organizada pelas historiadoras Victoria E. Bonnel e Lynn Hunt. De Frank Ankersmit a Hayden White, com menor ou maior incidência, procura-se preparar o leitor de maneira multivocal para a parte derradeira do artigo - O assombro da História: um jogo da vida e da morte - quando, enfim, invoca-se Shakespeare e o assombro de Hamlet em perspectiva certeauniana, em um diálogo tenro com a psicanálise. Sem enrijecer os preceitos teóricos de quaisquer posições epistemológicas, pretende-se fazê-lo como recomenda o próprio Certeau: "reciprocamente, a citação é o meio de articular o texto a sua exterioridade semântica, de permitir-lhe fazer de conta que assume uma parte da cultura e de lhe assegurar, assim, uma credibilidade referencial” (CERTEAU, 2011, p. 102).

\section{A passagem do historiador à escrita}

Entre outras coisas, o historiador promove a passagem da prática no interior de uma "operação historiográfica" - como exercício de "prefiguração textual” - à escrita da História. Ao realizar a passagem da prática à escrita da História, o historiador faz com que haja um passado do texto - um outro hegemônico e multiforme: escrever a História é não somente construir as representações do passado (ANKERSMIT, 2012), mas fazer com que 

consciência humana, um componente inevitável das instituições, valores e outros padrões da sociedade humana" (HOBSBAWM, 2013, p. 25). Embora tenha vinculado, neste fragmento textual, o passado às instituições, aos valores e aos padrões das sociedades, Hobsbawm aduziu que se trata de uma dimensão permanente da consciência humana. Sabe-se, pois, que o que quer que tenha passado está, de forma aproximada ou distada, mais ou menos presente na consciência humana - da objetividade documental à subjetividade. E o texto tem passado, indica pretéritos: coleções documentais, seriações, análises; o texto é, nesse sentido, um artefato criativo e deflagrado. Mas, note-se, Certeau reconhecia a escrita da História não como a extinção da pesquisa que a originou: “enquanto a pesquisa é interminável, o texto deve ter um fim, e esta estrutura de parada chega até a introdução, já organizada pelo dever de terminar” (CERTEAU, 2011, p. 90). Donde, a escrita da História nasce com o dever de terminar, de encerrar, de acabar, porque finda no domínio do historiador e se desloca à esfera evidente da interpretação do leitor. No entanto, terminar não é somente um gesto difícil, mas fundacional - um texto começa quando terminada a sua produção; quando o historiador, enquanto criador, enquanto artífice, termina a feitura.

Sem ser uma espécie de "sacerdote textual", o historiador media, promove e facilita a operação ao "trançar os fios" de uma passagem - da prefiguração à escrita da História: "a história é bem a ciência do passado, com a condição de saber que este passado se torna objeto da história, por uma reconstrução incessantemente reposta em causa" (LE GOFF, 2003, p. 26); ulteriormente, é o historiador quem empresta o seu nome ao conjunto organizado de (res)significantes que ele mesmo (des)construiu. Responsabiliza-se, assim, pela historiografia para que haja uma unidade ainda que passageira - uma ilusão original, com o devaneio preciso de começar, com a coragem de terminar sem impor: o conjunto apresenta-se como uma arquitetura "estável de elementos, de regras e de conceitos históricos que constituem sistema entre si e cuja coerência vem de uma unidade designada pelo próprio nome do autor" (CERTEAU, 2011, 
p. 90). Nada obstante, o historiador, advertiu Marc Bloch, desde as origens dos Annales, tem o fito da análise compreensiva das diferentes tendências, dos diferentes acontecimentos no (de)curso do tempo; não julga como "juiz dos infernos, encarregado de distribuir o elogio ou o vitupério aos heróis mortos", mas, sem prescindir da análise, tenciona principalmente compreender, entender, desnudar: "assim como todo cientista, como todo cérebro que, simplesmente, percebe, o historiador escolhe e tria. Em uma palavra, analisa" (BLOCH, 2001, p. 125-128). Ora, a passagem da "lacuna" - do "vazio" que subjaz no trabalho de pesquisa - ao seu preenchimento por meio da atividade criativa de uma escrita da História, verte-se ao "reino do discurso" porque "por esses poucos traços - a inversão da ordem, o encerramento do texto, a substituição de um trabalho de lacuna por uma presença de sentido - pode-se medir a servidão que o discurso impõe à pesquisa" (CERTEAU, 2011, p. 91).

Por essa razão destacada entre outras, Roger Chartier ponderou, de maneira assertiva, que Certeau se tornou "o historiador mais atento às propriedades formais do discurso histórico, colocado e diferenciado dentro da classe dos relatos" (CHARTIER, 2015, p. 14-15). Chartier disse, portanto, ao buscar fulcro dialógico na produção de Certeau, que a História, como escritura, "está desdobrada, folheada, fragmentada" e que "tem, então, a tripla tarefa de convocar o passado, que já não está num discurso no presente; mostrar as competências do historiador, dono das fontes; e convencer o leitor" (CHARTIER, 2015, p. 15). Na passagem à escrita da História, e no convencimento embasado do leitor, o historiador propicia reconhecidamente elementos hermenêuticos à confecção textual porque constrói, entre outras coisas, uma "escrita em espelho"3, uma "inversão":

\footnotetext{
${ }^{3}$ Das inversões comuns na prática das crianças em fase de letramento/alfabetização, considera-se, com Jaime Luiz Zorzi, que as "letras são giradas em relação ao próprio eixo, como é o caso de uma troca entre b e d, por exemplo"; mas também pode-se considerar como inversões a ocorrência de mudanças quanto à posição das letras dentro das palavras, por exemplo na situação em que "espada" é escrita como "sepada", que se caracteriza por uma inversão de posições entre as letras "e" e "s". In: <http://www.cefac.br/library/artigos/3c269d1d920ea45f9274741052c717a4.pdf>. Acesso no dia 3 de novembro de 2016.
} 
A escrita seria, então, a imagem invertida da prática? Teria, como nas criptografias, nos jogos de crianças ou nas imitações de moedas pelos falsários, o valor da escrita em espelho, ficção fabricadora de enganos e de segredos, trançando a cifra de um silêncio pela inversão de uma prática normativa e de sua condição social. Assim acontece no caso do Miroirs de l'Histoire [...] A escrita em espelho é séria por causa do que faz - dizer outra coisa pela reversão do código das práticas -; ela é ilusória apenas na medida em que, por não se saber o que faz, tender-se-ia a identificar o seu segredo ao que põe na linguagem e não ao que dela subtrai. (CERTEAU, 2011, p. 91)

Por isso, os jogos e as práticas - as "estratégias espelhadas" - pregressas, em contato com os segredos, os documentos e o labor contidos na pesquisa, na observação, na consulta, transferem-se à linguagem, ao texto - numa escrita em espelho não como defeito, mas como estratégia historiográfica. Por outros motivos não tão distantes dos apresentados neste artigo, mas também pelas inovações de Certeau em contato com as ditas novas tendências historiográficas, Chartier pergunta sobre sua teoria: "isso significa, então, que não há aí mais que um teatro da erudição que de modo algum dá à história a possibilidade de produzir um conhecimento adequado do passado?". Ao apresentar a indagação anterior, Chartier não abdicou de sua posição acerca da importância da teoria de Certeau no que tange ao discurso, à narrativa e à persuasão, mas, ao contrário, considerou a chamada firmeza deste autor sobre a História como "conhecimento", como “disciplina” articulada a um lugar de produção: para Certeau, a História "é um discurso que produz enunciados científicos" (CHARTIER, 2015, p. 15 - 16). Ao mencionar, ainda, que Certeau considerou a História como ciência capaz de estabelecer um conjunto de regras que "permitam 'controlar' operações proporcionais à produção de objetos determinados", Chartier explicou que:

produção de objetos determinados remete à construção do objeto histórico pelo historiador, já que o passado nunca é um objeto que já está ali; "operações" designa as práticas próprias da tarefa do historiador (recorte e processamento das fontes, mobilização de técnicas de análise específica, construção de hipótese, procedimentos de verificação); "regras" e "controles" inscrevem a história em um regime de saber compartilhado, definido por critérios de prova dotados de uma validade universal. (CHARTIER, 2015, p. 16) 
Nesse sentido - tanto quanto em Carlo Ginzburg - se encontram justapostos conhecimento e relato, prova e retórica, saber crítico e narração, conforme Chartier. Na confluência dos elementos justapostos mencionados - sem grandes disjunções como em Michel Foucault lido também por Hayden White, estabelece-se a sua relação com a História como ciência ocupada com o leitor, com a sua função didática e ao modo da passagem à escrita: a História é "uma prática social que confere ao seu leitor um lugar bem determinado, redistribuindo o espaço das referências simbólicas e impondo, assim, uma 'lição'; ela é didática e magisterial”; mas, ao mesmo tempo, na perspectiva da “escrita em espelho", ela permanece "funcionado como imagem invertida" porque "dá lugar à falta e a esconde; cria esses relatos do passado que são o equivalente dos cemitérios nas cidades" (CERTEAU, 2011, p. 91 - 92). A História, então, "exorciza e reconhece uma presença da morte" porquanto não somente produz a dialogia intratextual, os códigos, os sentidos e mesmo a ausência deles, mas, outrossim, traz a lume os ausentes na passagem da prática, da pesquisa, à presença da textualidade como textura - uma invocação de mortos na própria historiografia, na utilização do labor no trato com o corpus documental: entralha-se "mortos-agora-vivos" em material nu. Daí, o historiador produz a convivência, na escrita em verso e reverso, na "escrita em espelho", do trabalho que tenciona "fazer história", conforme apontou Jean-Pierre Faye, e, concomitantemente, “contar histórias": das "violências de um poder" às escapatórias; donde, instaura-se, no fazer a História, no contar as histórias, portanto, uma instrução que pode até mesmo divertir por meio dos interstícios do cotidiano.

Salvaguardadas as diferenças teóricas entre Hayden White e Certeau no que tange aos aspectos teóricos e aos lugares de produção, bem como as importantes ressalvas e considerações que têm feito os teóricos como José Antonio Vasconcelos (2005), sabe-se, com White, que a "história é o tema desse aprendizado que só é acessível por meio da linguagem" (WHITE, 2001, p. 31); e a escrita da História, entre fazer a História e contar as histórias articuladas por meio da operação historiográfica às estratégias da própria escrita, da historiografia, compreende a atividade, o ofício do historiador: "o gesto que liga as "ideias" aos lugares é, precisamente, um gesto de historiador: e, sem deixar o rigor do que compreendeu ser uma ciência, Certeau aduziu que: compreender é "analisar em 
termos de produções localizáveis o material que cada método instaurou inicialmente segundo seus métodos de pertinência" (CERTEAU, 2011, p. 45).

E a escrita em espelho de Certeau, como estratégia que vincula e desvincula opostos, na contramão de uma história-plenamente-aceita, de uma "história-verdade", pretende-se como desperta diante dos jogos de poder -, em que se subverte a noção maior, a teleologia vulgar, o axioma antigo; posto que, para White, a "nossa experiência da história é indissociável de nosso discurso sobre ela; esse discurso tem que ser escrito antes de poder ser digerido como história" (WHITE, 2001, p. 31). Da prática à escrita se tem, pois, o "trabalho cotidiano, das eventualidades, dos conflitos, das combinações de microdecisões que caracterizam a pesquisa concreta, o discurso se situa fora da experiência que lhe confere crédito", porque se dissocia "do tempo que passa, esquece o escoamento dos trabalhos e dos dias para fornecer 'modelos' no quadro 'fictício' do tempo passado" (WHITE, 2001, p. 92). Mas, o que é escrever para Certeau? A partir de “A Invenção do Cotidiano: Artes de Fazer", concebe-se a escrita como sendo: "a atividade concreta que consiste, sobre um espaço próprio, a página, em construir um texto que tem poder sobre a exterioridade da qual foi previamente isolado" (CERTEAU, 1998, p. 225).

Nesse sentido existem três componentes importantes subjacentes na "escrita do cotidiano", e na escrita da História, destacados por Certeau nos excertos elencados abaixo:

Primeiro:

a página em branco: um espaço "próprio" circunscreve um lugar de produção para o sujeito. Trata-se de um lugar desenfeitiçado das ambiguidades do mundo. Estabelece o afastamento e a distância de um sujeito em relação a uma área de atividades. Oferece-se a uma operação parcial mas controlável. Efetua-se um corte no cosmos tradicional, onde o sujeito era possuído pelas vozes do mundo. Coloca-se uma superfície autônoma sob o olhar do sujeito que assim dá a si mesmo o campo de um fazer próprio. Gesto cartesiano de um corte instaurador, com um lugar de escritura, do domínio (e isolamento) de um sujeito diante de um objeto. Diante de sua página em branco cada criança já se acha posta na posição do industrial ou do urbanista, ou do filósofo cartesiano - aquela de ter que gerir o espaço, próprio e distinto, onde executar um querer próprio. (CERTEAU, 1998, p. 225) 
Segundo:

aí se constrói um texto. Fragmentos ou materiais linguísticos são tratados (usinados, poder-se-ia dizer) neste espaço, segundo métodos explicitáveis e de modo a produzir uma ordem. Uma série de operações articuladas (gestuais e mentais) - literalmente é isto, escrever, - vai traçando na página as trajetórias que desenham palavras, frases e, enfim, um sistema. Noutras palavras, na página em branco, uma prática itinerante, progressiva e regulamentada - uma caminhada - compõe o artefato de um outro "mundo", agora não recebido, mas fabricado. 0 modelo de uma razão produtora escreve-se sobre o não-lugar da folha de papel. Sob formas múltiplas, este texto construído num espaço próprio é a utopia fundamental e generalizada do Ocidente moderno. (CERTEAU, 1998, p. 225)

Terceiro:

esta construção não é apenas um jogo. Sem dúvida, em toda sociedade, o jogo é um teatro onde se representa a formalidade das práticas, mas tem como condição de possibilidade o fato de ser distinto das práticas sociais efetivas. Pelo contrário, o jogo escriturístico, produção de um sistema, espaço de formalização, tem como "sentido" remeter à realidade de que se distinguiu em vista de mudáde encontre-la. Tem como alvo uma eficácia social. Atua sobre a sua exterioridade. O laboratório da escritura tem como função "estratégica": ou fazer que uma informação recebida da tradição ou de fora se encontre aí coligada, classificada, imbricada num sistema e, assim, transformada; ou fazer que as regras e os modelos elaborados neste lugar excepcional permitam agir sobre o meio e transformá-lo. A ilha da página é um local de passagem onde se opera uma inversão industrial: o que entra nela é um "recebido", e o que sai dela é um "produto". As coisas que entram na página são sinais de uma "passividade" do sujeito em face de uma tradição; aquelas que saem dela são as marcas do seu poder de fabricar objetos. No final das contas, a empresa escriturística transforma ou conserva dentro de si aquilo que recebe do seu meio circunstancial e cria dentro de si os instrumentos de uma apropriação do espaço exterior. (CERTEAU, 1998, p. 225 - 226).

Da página em branco - como espaço de escritura - onde se operacionaliza uma presença como superação do passado de uma prática, do passado lacunar, do passado de um ausente, até a construção textual a partir do modelo de uma razão sobre o não-lugar; e, então, engendra-se a fabricação, a escultura, de um produto que aponta para, ulteriormente, a recepção da escritura em um espaço exterior, em um espaço do leitor 
“escrita em espelho", arte da inversão do dogma, arte da escrita sub-reptícia que faz a reviravolta no poder da escrita e confere legitimidade às estratégias de um historiador não convencido - ou permanentemente inquieto - com as evidências (CERTEAU, 2011, p. 93).

\section{O espectro da morte na escrita da história}

Ao identificar uma série de personagens - não somente os chamados "grandes homens", o historiador, irrestrito à concepção da "história do tempo presente", coleciona os nomes próprios sob os seus olhares analíticos, sob as suas percepções atentas. No mor das vezes, tais nomes próprios são os dos mortos - fugídios: uma galeria de mortos se apresenta ao historiador que, por sua vez, busca a exumação das suas histórias, a exumação dos seus vestígios postos em perspectivas, postos em escrita(s). Os mortos estão situados em diferentes e alternantes temporalidades - desde, por exemplo,

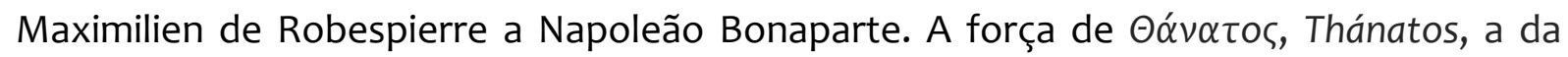
morte, apresenta-se ao historiador que, como vivo, beira à morte e a concita ao desafio de remodelagem em sua escrita da História: não que dê a vida ao morto para além da linguagem, mas que dê o morto à narrativa por presente. Se para o historiador a escrita da História é uma escrita de mortos, ele mesmo incorre na estratégia do passado que propõe decifrar: é um moribundo que, segundo Certeau, invoca os espectros e os analisa - procede necropsia para jogar com metáforas, na "subversão dos mundos", na escrita sub-reptícia - "desse ponto de vista, o escritor é também o moribundo que tenta falar” (CERTEAU, 1998, p. 303).

Do conceito de Certeau, anuncia-se que "a escrita põe em cena uma população de mortos - personagens, mentalidades ou preços"; a partir de uma galeria, a História representa mortos no decorrer de um itinerário narrativo, e, portanto, "re-presenta" os nomes próprios porque muitos indícios atestam, na história, essa estrutura de galeria: 
“por exemplo, a multiplicação dos nomes próprios (personagens, localidades, moedas etc.) e sua reduplicação no "Index dos nomes próprios": aquilo que dessa maneira prolifera no discurso histórico são esses elementos "com os quais não se faz nada além de mostrar" e "através dos quais o dizer está no seu limite, o mais próximo do mostrar" (CERTEAU, 2011, p. 108-109). Destarte, o dizer está para um discurso de amostragem e para a pessoa do dito em sua feição representacional não raras vezes concebida distante do mundo tangível na ordem dos fatos rígidos; posto que não se invoca, em sentido conotativo, do mundo dos mortos uma verdade clássica que pode ser descrita com fixidez, com corporeidade, pode-se buscar um alhures com o movimento que visibiliza uma comunidade de mortos posta em galeria(s). São representações articuladas à operação historiográfica. Nesse sentido, invocam-se os mortos representados em toda a escrita da História possível.

Das representações, disse Frank Rudolf Ankersmit, entre outras coisas, que:

No caso de um retrato ou uma biografia de Napoleão, o que poderia representar, se não o próprio Napoleão? [...] se o que é representado por uma pintura ou uma biografia de Napoleão, não é o próprio Napoleão, o que poderia eventualmente ser isso, e como devemos então conceber a relação entre isto e o próprio Napoleão? Pense novamente na pinturaretrato. Nossa inclinação natural seria a de equiparar o representado a um objeto identificável e único no mundo, e dizer que, neste caso, o representado é a pessoa que foi pintada pelo artista. Mas, a intuição prova-se equívoca se considerarmos a situação em que temos várias pinturas (representações) de uma mesma pessoa - por exemplo, Napoleão como descrito por David, Baron Gros, Girodet-Trioson, Gillray etc. Essas representações são todas diferentes, e às vezes até de forma drástica (compare o Napoleão de David ao de Gillray), e se as representações são representações de um representado, os representados devem diferir também, na medida em que um representado é aquilo que é representado por uma representação. Isto obriga-nos a abandonar a visão de que o representado deve ser identificado com o modelo que se senta em frente ao pintor. Devemos rejeitar a identidade dos representados com o objeto de referência - e reconhecer que a identidade é uma projeção ilegítima da estrutura do enunciado sobre a representação. (ANKERSMIT, 2012, p. 189)

Dessa forma, ao escrever a História com respeito à documentação, à metodologia e à ciência como fundamentais aos compromissos epistêmicos e sociais do historiador, 
vem à tona ou aos feitos do morto, do grande ou pequeno morto, que teriam contribuído com mudanças e permanências históricas - a carne se faz verbo. Eis que os fatos quando (re)contados - possuem, pois, uma dimensão narrativa indissociável à sua descrição realizada por diferentes ângulos. Para Hobsbawm, Napoleão, que começou na vida militar como "pequeno cabo", galgou "o comando de um continente pelo seu puro talento pessoal (Isso não foi exatamente verdadeiro, mas sua ascensão foi suficientemente meteórica para tornar razoável a descrição): “todo jovem intelectual que devorasse livros, como o jovem Bonaparte o fizera, escrevesse maus poemas e romances e adorasse Rousseau poderia, a partir daí, ver o céu como limite e seu monograma envolvido em lauréis", mas “todo homem de negócios daí em diante tinha um nome para sua ambição: ser - os próprios clichês o denunciam - um napoleão das finanças ou da indústria; contudo, "todos os homens comuns ficavam excitados pela visão, então sem paralelo, de um homem comum que se tornou maior do que aqueles que tinham nascido para usar coroas" porque "Napoleão deu à ambição um nome pessoal no momento em que a dupla revolução tinha aberto o mundo aos homens de vontade" (HOBSBAWM, 2015, p. 130). Mas, lembre-se do óbvio, Napoleão está morto - as pinturas que o retratam e os textos que o historiam são representacionais: invocações do mundo dos mortos por meio de linguagens, narrativas, mentalidades que não prescindem, porém, da documentação colecionada pelos historiadores.

Se, no entanto, a "representação é uma operação de três lugares" - conforme propôs Ankersmit -, então, “uma representação (1) define um representado (2) em termos dos quais o mundo (3) é visto" (ANKERSMIT, 2012, p. 194). Quando nas categorias de Certeau, o representado é um ausente, um alhures, uma alteridade posta no passado inversão do presente, Napoleão, entre outros, ainda pode ser retratado ao invés de descrito com rigidez mesmo por um historiador marxista que não faz apologias às categorias teóricas representacionais: "foi o homem da Revolução, e o homem que trouxe estabilidade. Em síntese, foi a figura com que todo homem que partisse os laços 
com a tradição podia se identificar em seus sonhos" (HOBSBAWM, 2015, p. 131). Sabe-se que as artes operam sobre um código de sensibilidade que, de outra forma, e a partir de outras habilidades, não se afugenta necessariamente dos textos historiográficos: ambos comunicam - salvaguardadas as diferenças. Desse modo, reconhece-se que os pintores David e Gillray “teriam protestado veementemente se lhes disséssemos que as diferenças entre as suas representações de Napoleão foram meras questões acidentais", porque "ambos consideram que suas representações referem-se exatamente a uma mesma coisa, ou seja, Napoleão" (ANKERSMIT, 2012, p. 190).

Sobre a escrita historiográfica no tocante ao lugar do morto, e ao lugar do leitor, Certeau ponderou dois aspectos: "por um lado, no sentido etnológico e quase religioso do termo, a escrita representa o papel de um rito de sepultamento; ela exorciza a morte introduzindo-a no discurso" (CERTEAU, 2011, p. 109); trata-se, portanto, da passagem, do rito de sepultamento, que permite que o exorcismo da morte produza a transposição do morto, da galeria de mortos, para o texto historiográfico, para o universo da representação - ofício de historiador. Por outro lado,

tem uma função simbolizadora; permite a uma sociedade situar-se, dando-Ihe, na linguagem, um passado, e abrindo assim um espaço próprio para o presente: "marcar" um passado é dar um lugar à morte, mas também redistribuir o espaço das possibilidades, determinar negativamente aquilo que está por fazer e, consequentemente, utilizar a narratividade, que enterra mortos, como um meio de estabelecer um lugar para os vivos. A arrumação dos ausentes é o inverso de uma normatividade que visa ao leitor vivo, e que instaura uma relação didática entre o remetente e o destinatário. (CERTEAU, 2011, p. 109)

Em um viés criativo, a escrita da História oportuniza, por meio do seu "material narrativo", que o passado, ou a sua ausência lógica factual no agora, seja formador do espaço próprio para o presente - que o passado se constitua em um lugar do morto e o presente em um lugar do leitor -, isto é, para o lugar do vivo que o molda com fulcro na linguagem representacional. Ao se reconhecer, com Bloch, que "o passado é, por definição um dado que nada mais modificará", sepultá-lo como morto e reavê-lo posteriormente, indica, entretanto, a sua reinvenção iminente por meio de uma "boa história" - do "edênico" ao "hedônico"; "mas o conhecimento do passado é uma coisa 
em progresso, que incessantemente se transforma e aperfeiçoa" (BLOCH, 2001, p. 75). Ainda assim, Bloch, um dos fundadores da Escola dos Annales, não abdicou do documento em seu sentido crucial para o historiador: "os exploradores do passado não são homens completamente livres”, pois “o passado é seu tirano” porque "proíbe-lhes conhecer de si qualquer coisa a não ser o que ele mesmo lhes fornece [conscientemente ou não]" (BLOCH, 2001, p. 75). Com temporalidades e dinâmicas diferentes, o passado, no lugar do morto, produz lembranças nos vivos: ponto de contato da História com a memória; o "que é definido oficialmente como "passado" é e deve ser claramente uma seleção particular da infinidade daquilo que é lembrado ou capaz de ser lembrado" segundo circunstâncias variadas, assim como por diversas bases documentais (HOBSBAWM, 2013, p. 26).

Entre “pesquisa” e “texto”, o que a escrita da História constrói?

Ora, ela constrói um “túmulo":

No texto, o passado ocupa o lugar do assunto-rei. Uma conversão escriturária se operou. Lá onde a pesquisa efetuou uma crítica dos modelos presentes, a escrita construiu um "túmulo" para o morto. 0 lugar feito para o passado joga, pois, aqui e lá, com dois tipos de operação, uma técnica e outra escriturária. É apenas através dessa diferença de funcionamento que pode ser reencontrada uma analogia entre as duas posições do passado - na técnica de pesquisa e na representação do texto. A escrita não fala do passado senão para enterrá-lo. Ela é um túmulo no duplo sentido de que, através do mesmo texto, ela honra e elimina. (CERTEAU, 2011, p. 110)

Porque, para Certeau, pode-se dizer que a escrita da História "faz mortos para que os vivos existam" e ela desloca o passado ao campo do relato, ao campo do discurso mas, “diferentemente de outros 'túmulos' artísticos ou sociais, um lugar (passado ou futuro) a preencher, um dever-fazer", a escrita "acumula o produto desse trabalho", porque "através dele, libera o presente sem ter que nomeá-lo" (CERTEAU, 2011, p. 110). Funda-se o lugar do próprio, o lugar do texto, o lugar do presente. Evidentemente, escreve-se a História em longas ou curtas produções textuais; o texto é o lugar do morto honrado e literariamente eliminado em um espaço de presente e até da noção de futuro. Segundo Julia Kristeva, em uma definição aceita inclusive por Roland Barthes, entre 
anteriores, de Kristeva, são obviamente temporais, são passados, mas são passagens espaços de criação. E é nesse sentido do passado que Certeau afirma que "uma sociedade se dá um presente graças a uma escrita histórica", que o texto histórico - o qual tem "um papel performativo" - substitui o "ser ausente, prisão do gênio mau da morte", que a “linguagem permite a uma prática situar-se com relação ao seu outro, o passado": porque a "historiografia se serve da morte para articular uma lei (do presente)" (CERTEAU, 2011, p. $110-111)$.

Ainda assim, a linguagem que permite um outro observável, o passado, engendrase através de múltiplas leituras representacionais na perspectiva da sua morte, da sociedade bem presente que "semantiza" o lugar do morto - conforme Certeau. A força hermenêutica da sociedade pregressa repensada por historiadores, e da sociedade presente, articula-se ao que Chartier designou - ao citar Marcel Mauss e Emile Durkheim de a "representação coletiva". Isto é, em Chartier, neste aspecto, as representações do passado são feitas, de igual modo, em consideração à sociedade presente, à sociedade do nominado tempo presente. Porque, de saída, dá-se o "trabalho de classificação e de recorte que produz as configurações intelectuais múltiplas pelas quais a realidade é contraditoriamente construída pelos diferentes grupos que compõem uma sociedade" (CHARTIER, 2002, p. 73). Depreende-se, pois, que para além do historiador está o leitor, o qual apropria-se do passado com as "lentes da realidade" construída no âmbito de grupos díspares presentes na própria sociedade fragmentariamente analisada. Donde, em seguida, o leitor aguça-se na busca pelas "práticas que visam a fazer reconhecer uma identidade social, a exibir uma maneira própria de estar no mundo, a significar simbolicamente um estatuto e uma posição"; e, igualmente, em dedicar-se às "formas institucionalizadas e objetivadas graças às quais 'representantes' (instâncias coletivas ou indivíduos singulares) marcam de modo visível e perpetuado a existência do grupo, da comunidade ou da classe" (CHARTIER, 2002, p. 73). 
De que maneira, então, um grupo - com base na representação coletiva sustenta, em diferentes momentos, escrituras, leituras e a morte contida na escrita da História, na leitura da História? Com Ricoeur, reconhece-se que: "a história é uma escrita, de uma ponta a outra: dos arquivos aos textos de historiadores, escritos, publicados, dados a ler" (RICOEUR, 2007, p. 247); a morte e o presente estão por todos os lados mediados pela narrativa, pela linguagem, pela maneira como as histórias se constituem, se constroem. Cabe dizer que, em Certeau, a escrita da História tem um desdobramento crítico propugnado no interregno, no ritual, do "exorcismo da morte" e da sua colocação no relato, no discurso:

a escrita caminha entre a blasfêmia e a curiosidade, entre aquilo que elimina, constituindo-o como passado, e aquilo que organiza do presente, entre a privação ou a desapropriação postulada pela normatividade social que ela impõe ao leitor, à sua revelia. Por todos esses aspectos, combinados na encenação literária, ela simboliza o desejo que constitui a relação com o outro. Ela é a marca dessa lei.

Não é surpreendente que esteja em jogo, aqui, algo diferente do destino ou das possibilidades de uma "ciência objetiva". Na medida em que nossa relação com a linguagem é sempre uma relação com a morte, o discurso histórico é a representação privilegiada de uma "ciência do sujeito", e do sujeito "tomado numa divisão constituinte" - mas com a representação das relações que um corpo social mantém com a sua linguagem. (CERTEAU, 2011, p. 111)

Da noção de ciência objetiva, a História foi concebida por Certeau como sendo científica, sim, mas como científica nas categorias de uma "ciência do sujeito" que vincula a "representação das relações que um corpo social mantém com a sua linguagem" segundo constante acima (a linguagem é um protagonista inclusive certeauniano); para Jacques Lacan - cuja reflexão serviu para o texto de Certeau em diversos momentos de sua produção - "não existe ciência do homem, porque o homem da ciência não existe, mas apenas seu sujeito"4 (Apud CERTEAU, 2011, p. 111). O diálogo de Certeau com a psicanálise principalmente lacaniana - estruturalista, com a ficção, com a literatura, com a linguagem e com a narrativa foi demonstrado com suficiência em sua obra "História e Psicanálise: entre ciência e ficção" (CERTEAU, 2012). Resta-nos, pois, conceber a escrita

\footnotetext{
${ }^{4}$ Ressalva-se que, neste artigo, não se pretende discutir a noção de "sujeito" na Filosofia, na psicanálise e na História. Tal discussão seria densa para as pretensões anunciadas na "apresentação" deste texto.
} 
representa, utiliza esse lugar para impor um querer, um saber e uma lição ao destinatário": encontra "apoio, precisamente, naquilo que oculta: os mortos, dos quais fala, se tornam o vocabulário de uma tarefa a empreender". Donde, a escrita da história é a "denegação de uma ausência" e "age ora como discurso de uma lei”, "ora como álibi, ilusão realista (o efeito de real cria ficção de uma outra história)" entre produzir a história e contar as histórias (CERTEAU, 2011, p. 111). Depois, vem o “assombro".

\section{O assombro da História: "um jogo da vida e da morte"}

Para fazer alusão à escrita, as autoras Aline Magalhães Pinto e Manuella Luz de Oliveira Valinhas (2010) mencionaram Maurice Blanchot na descrição acerca da "historicidade, retórica e ficção" em diálogo com a teoria de Dominick LaCapra- que não é objeto de análise neste artigo. O excerto citado pelas autoras, porém, é o seguinte:

Escrever é entrar na afirmação da solidão onde o fascínio ameaça. É correr o risco da ausência de tempo, onde reina o eterno recomeço. É passar do Eu ao Ele, de modo que o que me acontece não acontece a ninguém, é anônimo pelo fato de que isso me diz respeito, repete-se numa disseminação infinita. Escrever é dispor a linguagem sob o fascínio e, por ela, nela, permanecer em contato com o meio absoluto, onde a coisa se torna imagem, de alusão a uma figura se converte em alusão ao que é sem figura e, de forma desenhada sobre a ausência torna-se a presença informe dessa ausência, a abertura opaca e vazia sobre o que é quando não há mais ninguém, quando ainda não há ninguém. (BLANCHOT, 1987, p. 20)

Na dinâmica do tempo discursivo - porque, em Certeau, o discurso avança mais ou menos rápido, conforme ele se retarde ou se precipite - a passagem do "eu ao ele" ocorre, como é óbvio, não do pretérito para o presente como no tempo sequencial ou teleológico, mas do presente em digressão analítica, em digressão representacional; mas, não em uma teleologia reversa em "contrapelo"; é escrita de ausências como sugeriu Blanchot: o morto está inexoravelmente no passado, portanto. A representação do 
teóricos contemporâneos"; porque sem uma relação entre o corpo social e a instituição de saber não existe, nas categorias de Certeau, um relato histórico: há um lugar operacional de onde se percebe o ausente, o passado, o alhures. Importa, entretanto, que ao se tornar "em alusão" do que "é sem figura" - com uma "presença informe dessa ausência", dos tempos em que "não há mais ninguém", a escrita da História encene, com critérios, o passado a partir de uma estratégia do tempo que inclui o autor, que inclui o leitor, que inclui a invocação de mortos e a sua consequente inserção no discurso do historiador como propôs, de outra forma, Fernando Catroga (2010). Para Certeau, então, duas estratégias do tempo são apresentadas interseccionadas entre a psicanálise e a História; ele mencionou Freud (1990), e, em particular, a sua predileção pela narrativa shakespeariana de Hamlet - ao descrever um episódio com lugar privilegiado nas acepções freudianas.

Em grandes linhas, quando o príncipe Hamlet soube da morte repentina do seu pai, ele retornou com rapidez à terra natal em uma narrativa que liga o luto e a decepção desconfiada sobre o ligeiro casamento de sua mãe Gertrudes com o seu tio Cláudio - cena deveras suspeita. Mas, Horácio, amigo de Hamlet, juntamente com dois oficiais, reporta ao príncipe que o fantasma do seu pai estava aparecendo recorrentemente na região do castelo da família. "Assombro da História": artefato literário? Ao buscar por respostas entre o(s) morto(s), o príncipe Hamlet foi informado pelo espectro do seu pai que ele, na verdade, havia sido assassinado por Cláudio - o seu tio que casou-se, por sua vez, com Gertrudes, sua mãe, e ocupou o trono no lugar do morto. Em encenações dramáticas e episódicas, o espectro pediu ao príncipe que se vingasse do assassino, agora, reinante no lugar do morto - porque havia um presente no lugar do passado; mas o Rei Hamlet solicitou ao filho que poupasse a própria mãe porque acreditava em uma possível punição divina em razão de torpe traição. Em molduras narrativas significativas, Shakespeare

\footnotetext{
${ }^{5}$ Para Certeau, o conhecimento da história é julgado mais por sua capacidade de medir exatamente os desvios - não apenas quantitativos (curvas de população, de salários ou de publicações), mas qualitativos (diferenças estruturais) - com relação às construções formais presentes" (2011, p. 86).
} 
Se você tem sentimentos naturais não deve tolerar; não deve tolerar que o leito real da Dinamarca sirva de palco à devassidão e ao incesto. Mas, seja qual for a tua forma de agir, não contamina tua alma deixando teu espírito engendrar coisa alguma contra tua mãe. Entrega-a ao céu e aos espinhos que tem dentro do peito: eles ferem e sangram. Adeus de uma vez! (SHAKESPEARE, 2004, p. $80-83$ )

Ao longo da peça, porém, tornou-se corriqueira a hesitação do príncipe na vingança confiada a ele pelo Rei Hamlet, pois, apesar de inicialmente decidido a assassinar seu tio Cláudio por vingança, o príncipe Hamlet verteu-se, com complacência, ao longo das cenas que se seguiram até os desfechos da "taça envenenada" na narrativa. Em termos psicanalíticos, Freud dedicou-se a compreender o caráter "patife" de Hamlet em categorias edípicas e disse: “Hamlet é capaz de fazer qualquer coisa - salvo vingar-se do homem que eliminou seu pai e tomou o lugar deste junto a sua mãe, o homem que lhe mostra os desejos recalcados da sua própria infância realizados" (Apud SOUZA, 2006, p. 147). Conforme Mauricio Rodrigues de Souza, entre outras interpretações correntes, pode-se "inferir que se torne difícil para Hamlet executar a ordem homicida do fantasma, por uma identificação inconsciente com Cláudio", pois, “este último, a despeito das suas qualidades de assassino e usurpador do trono da Dinamarca, também representa o homem que conseguiu viabilizar o duplo desejo infantil e edipiano do próprio príncipe, ao afastar de seu caminho um rival monopolizador”, e, não obstante, "tomar para si a sua mulher" (SOUZA, 2006, p. 148). Em categorias edípicas e não edípicas, portanto, diferentes interpretações foram oferecidas, conforme se disse anteriormente, às posturas de Hamlet, às de Cláudio, às de Gertrudes - entre outros personagens (JONES, 1970; MEZAN, 1998); porém, Certeau enunciou o caráter assombroso da experiência com o Rei Hamlet - morto, falante; astúcia da História: “depois de ter sido assassinado, o pai de Hamlet retorna, mas como fantasma, em outra cena, e é, então, que ele se torna a lei à qual o filho obedece", embora se tenha constatado a hesitação supramencionada (CERTEAU, 2012, p. 71). 
Nesse sentido, abalizou:

O morto assombra o vivo; ele re-morde (mordida secreta e repetida). Assim, a história seria "canibal", e a memória tornar-se-ia o recinto fechado em que se opõem duas operações contrárias: por um lado, o esquecimento, que não é uma passividade nem uma perda, mas uma ação contra o passado; e, por outro, o vestígio mnésico que é o retorno do esquecido, ou seja uma ação desse passado, daqui em diante forçado ao disfarce [...] A historiografia desenvolve-se, pelo contrário, em função de um corte entre o passado e o presente. Ela é o resultado das relações de saber e de poder entre dois lugares supostamente distintos: por um lado, o lugar presente (científico, profissional, social) do trabalho, o aparato técnico e conceitual da pesquisa e da interpretação, a operação de descrever e/ou explicar; e, por outro, os lugares (museus, arquivos, bibliotecas) em que são guardados, inertes, os materiais que são objetos da pesquisa e - em um segundo momento, deslocados no tempo - os sistemas ou acontecimentos do passado, cuja análise é permitida por intermédio desses materiais. (CERTEAU, 2012, p. 71-72)

Depreende-se, pois, que a escrita da História, por um lado, exuma os mortos ou revela as surpresas de seus vultos com todas as implicações da prática que os trazem à tona em termos narrativos, ficcionais ou literários, e, por outro lado, revivesce uma população de mortos ao considerar o aspecto/espectro coletivo, vinculante, da própria História ou da memória como conjunto de lembranças coexistentes e alinhadas em sociedade (HALBWACHS, 1990). Se a História traz o espectro manifesto narrativamente, e de forma historiográfica, na voracidade, no canibalismo, conforme o excerto acima, a memória, por seu turno, lida com o esquecimento, com a lembrança e com as estratégias de recordações - também do apagamento. Ao mesmo tempo, a escrita da História pode ser concebida como assombro na medida em que a invocação representacional - literária - do mundo dos mortos por meio de vestígios, tais como os advindos dos documentos escritos, orais, entre outros, instaura-se com o retorno ligeiro, repentino, do ausente; destaque-se que tais mortos, quando exumados, quando invocados, apresentam as suas demandas em semelhança da peça shakespeariana sobre Hamlet: eles falam. Em cena, encena, o "discurso sobre o passado tem como estatuto ser o discurso do morto", ressalte-se, e, por isso, “o objeto que nele circula não é senão o ausente, enquanto o seu sentido é o de ser uma linguagem entre o narrador e os seus leitores, quer dizer, entre presentes": o morto é, assim, a "figura objetiva de uma troca entre vivos", pois que 
"enunciado do discurso que o transporta como um objeto, mas em função de uma interlocução remetida para fora do discurso, no não dito" (CERTEAU, 2011, p. 41). Assim, Certeau considerou as dimensões psicanalítica e histórica na escrita do texto ao ponderar a própria História tanto quanto a memória problematizada por ela, mas com notáveis diferenças temporais entre os dois campos científicos:

A psicanálise e a historiografia têm, portanto, duas maneiras diferentes de distribuir o espaço da memória; elas pensam, de modo diferente, a relação do passado com o presente. A primeira reconhece um no outro; quanto a segunda coloca um ao lado do outro. A psicanálise trata essa relação segundo o modelo da imbricação (um no lugar do outro), da repetição (um reproduz o outro sob uma forma diferente), do equívoco e do quiproquó (o que está "no lugar" de quê? Há, por toda parte, jogos de máscaras, de reviravolta e de ambiguidade). Por sua vez, a historiografia considera essa relação segundo o modelo da sucessividade (um depois do outro), da correlação (maior ou menor grau de proximidade), do efeito (um segue o outro) e da disjunção (um ou o outro, mas não os dois ao mesmo tempo). (CERTEAU, 2012, p. 73)

Porque na psicanálise o passado pode ser reconhecido no presente, considera-se fazer a análise propriamente dita: segundo Lacan, o analista é "todo aquele que, situado na posição de supostamente saber, apercebeu-se e não esquece o que é conteúdo desse saber; por conseguinte, torna-se capaz de operar com essa conjuntura". Concomitantemente, o analista, segundo Certeau, não se identifica com esse lugar, com o lugar do analisando, e, portanto, "nem transforma o que lhe é oferecido em um objeto de fruição" - pois, a sua "fórmula seria: "só existe isso", ou seja, a "mentira”, mas esta frustra "meu desejo" (o desejo do analisando), "não é isso" (CERTEAU, 2012, p. 218 - 219). Ainda nos termos de Certeau em diálogo com Lacan, o "analisando conserva incessantemente a preocupação em proteger o saber que ele supõe no outro; receia não tanto ser iludido, mas enganar seu analista"; ao passo que, segundo Freud, o analista busca o lugar do passado, um significante (um "pedacinho de verdade") na fala (CERTEAU, 2012, p. 219-221). No entanto, o historiador, ao escrever a História, estabelece, com escopo firme e significantes que dançam - sentido do discurso, o passado ao lado do presente: sucessão de eventos com base em documentos, elementos próximos ou distantes, mudanças e permanências, consequências ou inconsequências, escolhas entre representações múltiplas contidas nos meandros historiográficos ou as particularidades 
de uma história vista de baixo, de cima, de lado, de frente, por trás: os excertos se entendem. Que o passado esteja no presente como querem os psicanalistas, que esteja ao lado do presente como concebem os historiadores, pondera-se que, entretanto, este passado seja, ele próprio, um ausente, um outro, um alhures, um morto que, se avocado, produz o assombro semelhante ao shakespeariano.

Para Certeau,

No modo dessas conjugações com o ausente, a história se torna o mito da linguagem. Ela torna manifesta a condição do discurso: uma morte [...] Mas o ausente é também a forma presente da origem [...] A origem é interna ao discurso [...] O discurso não deixa de se articular com a morte que postula, mas que a prática histórica contradiz. Pois falar de mortos é também negar a morte e, quase, desafiá-la. Igualmente diz-se que a história os "ressuscita". Essa palavra é um engodo: ela não ressuscita nada. Mas evoca a função outorgada a uma disciplina que trata a morte como um objeto do saber e, fazendo isso, dá lugar à produção de uma troca entre vivos. (CERTEAU, 2011, p. $41-42$ )

Se a escrita da História - segundo preconizou Certeau - é "um jogo da vida e da morte" que prossegue no "calmo desdobramento de um relato, ressurgência e denegação da origem, desvelamento de um passado morto e resultado de uma prática ausente", os seus assombros, os seus espectros conferem-lhe surpresas entre linguagens, narrativas, representações, "diegesis" (BRANDT In PRADA, 1978). Ainda assim, diga-se, é historiográfica a escrita que procura compreender o seu outro, isto é, o seu passado como alteridade, os seus mortos (CERTEAU, 2011, p. 100). Sem novidades, "a carne se faz palavra". Diante da passagem do tempo, da escrita da História e da (des)ordem dos acontecimentos, bem como do "assombro" narrativo, o escritor, o historiador, seria também um "moribundo" conforme aventou Certeau (1998, p. 303) em a "Invenção do Cotidiano: Artes de fazer". De minha parte, penso: uma espécie de morto do amanhã. 


\section{Referências}

ANKERSMIT, Frank Rudolf. A escrita da história: a natureza da representação histórica. Londrina: UdUEL, 2012.

BARTHES, Roland. I: teoria. São Paulo: Martins Fontes, 2004.

BLANCHOT, Maurice. O espaço literário. Rio de Janeiro: Rocco, 1987.

BLOCH, Marc. Apologia da história, ou, o ofício do historiador. Rio de Janeiro: Jorge Zahar Ed, 2001.

BONELL, Victoria; HUNT, Lynn. Beyond the cultural turn: new directions the study of society and culture. Berkeley and Los Angeles: University of California Press, 1999.

BURKE, Peter. A Revolução Francesa da historiografia: a Escola dos Annales 1929 - 1989. São Paulo: Editora Universidade Estadual Paulista, 1991.

CATROGA, Fernando. O culto dos mortos como uma poética da ausência. ArtCultura, Uberlândia, v. 12, n. 20, p.163-182, jan./jun. 2010.

CERTEAU, Michel de. A escrita da história. Rio de Janeiro: Forense, 2011.

CERTEAU, Michel de. A invenção do cotidiano: artes de fazer. Petrópolis: Vozes, 1998.

CERTEAU, Michel de. História e psicanálise: entre ciência e ficção. Belo Horizonte: Autêntica Editora, 2012.

CHARTIER, Roger. On the edge of the cliff: history, language and practices. Baltimore: Johns Hopkins, 1997.

CHARTIER, Roger. À beira da falésia: a história entre incertezas e inquietudes. Porto Alegre: Editora Universidade, 2002.

CHARTIER, Roger. A história ou a leitura do tempo. Belo Horizonte: Autêntica Editora, 2015.

DOSSE, François. Michel de Certeau, le marcheur blessé. Paris: La Découverte, $2002 a$.

DOSSE, François. “Michel de Certeau, jalons d'un itinéraire”. EspacesTemps.net, Laboratoire, Paris, 2002b. 
FREUD, Sigmund. A interpretação dos sonhos: v. 5. Rio de Janeiro, Imago, 1990. Edição Eletrônica Brasileira das Obras Psicológicas Completas de Sigmund Freud.

HALBWACHS, Maurice. A memória coletiva. São Paulo: Vertice, 1990.

HOBSBAWM, Eric. A era das revoluções, 17890 1848. Rio de Janeiro: Paz e Terra, 2015.

HOBSBAWM, Eric. Sobre história. São Paulo Companhia das Letras, 2013.

IGGERS, Gorg G. Historiography in the twentieth century: from scientific objectivity to the postmodern challenge. Hanover: Wesleyan University Press, 1997.

JONES, Ernest. Hamlet e o complexo de Édipo. Rio de Janeiro: Zahar, 1970.

LACAN, Jacques. Hamlet por Lacan. São Paulo: Escuta, 1986.

LE GOFF, Jacques. História e memória. Campinas: Editora da UNICAMP, 2003.

MEZAN, Renato. Freud: a trama dos conceitos. São Paulo: Perspectiva, 1998.

PINTO, Aline Magalhães; VALINHAS, Mannuella Luz de Oliveira. Historicidade, retórica e ficção: interlocuções com a historiografia de Dominick LaCapra. Revista Rhêtorikê, n.3. p.1-18, Jun., 2010.

PRADA, Renato Oropeza. Linguistica y literatura. Xalapa, Mexico: Univ. Veracruzana, 1978.

RICOEUR, Paul. A memória, a história, o esquecimento. Campinas: Editora da Unicamp, 2007.

SHAKESPEARE, William. Hamlet: príncipe da Dinamarca. São Paulo: Peixoto Neto. 2004. (Trabalho original publicado em 1601),

SOUZA, Maurício Rodrigues de. Psicanálise e o complexo de Édipo: (novas) Observações a partir de Hamlet. Psicologia USP, 2006, 17 (2), 135-155.

VASCONCELOS, José Antonio. A história e a sedução da narrativa. Revista Uniandrade, v.11, n.02, Jul./dez., 2010.

VASCONCELOS, José Antonio. Quem tem medo de teoria? a ameaça do pós-modernismo na historiografia americana. São Paulo: Annablume; FAPESP, 2005. 
WHITE, Hayden. Trópicos do discurso: ensaios sobre a crítica da cultura. São Paulo: Editora da Universidade de São Paulo, 2001.

ZORZI, Jaime Luiz. As inversões de letras na escrita: o fantasma do espelhamento. São Paulo, 2000. Disponível em:

http://www.cefac.br/library/artigos/3c269d1d920ea45f9274741052c717a4.pdf> Acesso em 03/11/2016. 